\title{
Direito à saúde: escrever em defesa de um direito fundamental
}

\author{
Right to health: Writing in support on a fundamental right
}

\section{Paula Lobato de Faria}

Professora Associada de Direito da Saúde da Escola Nacional de Saúde Pública da Universidade Nova de Lisboa, Portugal. Membro da Comissão Diretiva da Rede IberoAmericana de Direito Sanitário.

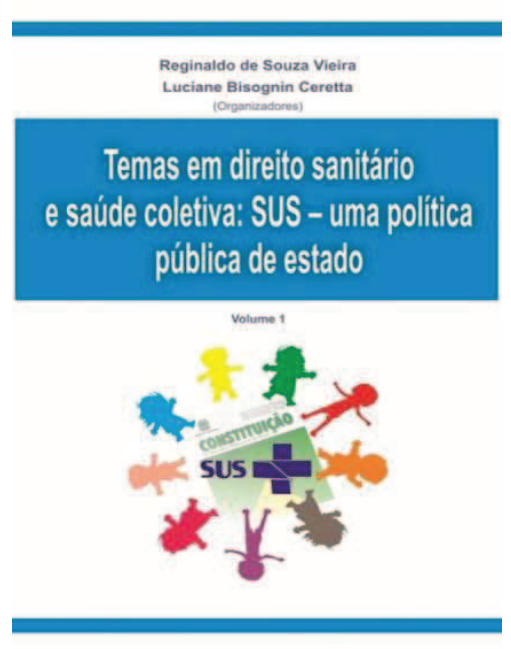

O livro Temas em Direito Sanitário e Saúde Coletiva, coordenado por Luciane Bisognin Ceretta e Reginaldo de Souza Vieira, com prefácio de Maria Célia Delduque e contando com a colaboração de muitos outros ilustres acadêmicos e profissionais do Direito Sanitário, foi lançado no dia 4 de outubro de 2013, durante o III Congresso Ibero-Americano de Direito Sanitário, realisado na cidade de Brasília.

A obra é fruto do trabalho desenvolvido pelo Laboratório de Direito Sanitário e Saúde Coletiva da Universidade do Extremo Sul Catarinense (LADSSC-UNESC) e das comunicações proferidas no I Seminário Sul-Brasileiro em Direito Sanitário e Saúde Coletiva realizado nas dependências da UNESC nos dias 17 e 18 de outubro de 2011. Insere-se na produção académica cuja nobre missão é a garantia do direito à saúde, direito fundamental, consagrado na Constituição da República Federativa do Brasil de 1988, em que o SUS - Sistema Único de Saúde, também previsto na Lei Fundamental brasileira, é a sua concretização sociopolítica mais emblemática. 
A contribuição desta publicação para este desígnio é muito rica, dado que contém capítulos bem fundamentados e plenos de referências bibliográficas recentes e de grande interesse, dividindo-se em duas grandes partes: a primeira dedicada ao "Estado, políticas públicas, direito à saúde e controle social" e a segunda, à "Saúde coletiva, integralidade e educação e saúde". Desenvolve-se por 14 capítulos, onde se analisam de forma abrangente temas de fundo, como os fundamentos teóricos do direito à saúde e as políticas nacionais de atenção básica da saúde e temas específicos, relacionados quer com grupos vulneráveis da população, de que são exemplo as crianças, os adolescentes e as mulheres reclusas, quer com as estruturas administrativas relevantes para a persecução das políticas públicas de saúde, como o Ministério Público, os Conselhos de Saúde e as agências reguladoras.

Os títulos e autores dos diversos capítulos são os seguintes:

\section{Parte I - Estado, políticas públicas, direito à saúde e controle social}

Capítulo I - Estado democrático de direito. Políticas públicas e direito à saúde: uma breve introdução sobre o SUS (Letícia Canut);

Capítulo II - Bioética e saúde coletiva: as vozes do direito à saúde (Felipa Rafaela Amadigi e Flávia Regina Souza Ramos);

Capítulo III - Estratégia saúde da família e a dicotomia política de Estado e política de governo: a busca pela efetivação do direito à saúde no Brasil (Andressa Fracaro Cavalheiro);

Capítulo IV - O direito à saúde como um direito fundamental à criança e ao adolescente normatizado no ordenamento jurídico brasileiro (Fernanda da Silva Lima e Juliana Paganini);

Capítulo V - O papel do Ministério Público na efetivação do direito ao acompanhante durante o trabalho de part, parto e pós-parto (Tailine Fátima Hijaz, Henrique Furlanetto V. Miranda e Reginaldo de Souza Vieira);

Capítulo VI - Os espaços das conferências e conselhos de saúde nos anos de 1990 e 2000 (Tânia Regina Krüger);

Capítulo VII - Democracia sanitária e as consultas públicas nas agências reguladoras de saúde (Sandra Mara Campos Alves). 


\section{Parte II - Saúde coletiva, integralidade e educação e saúde}

Capítulo I - O sistema único de saúde e a política nacional de atenção básica da saúde (Roseli Schminski Vieira, Reginaldo de Souza Vieira e Ivanir Prá da Silva);

Capítulo II - A Política Nacional de Promoção da Saúde e seu paradigma na enfermagem (Priscila Rosa Maceno, Michelle Kuntz Durand, Ivonete T.S. Buss Heidemann, Karine Patricia Stulp e Ana Izabel Jatobá de Souza);

Capítulo III - O acolhimento e o vínculo como instrumentos para a integralidade do cuidado em saúde na perspectiva de um grupo de diabéticos (Luciane Besognin Ceretta, Mágada Tessmann Schwalm, Karina Gulbis Cardoso Zimermann, Cerinéia de Macedo e Lisiane Tuon Generoso Bitencourt);

Capítulo IV - Vivência de mulheres reclusas (Iona Vieira Bez Birolo, Vera Radünz, Sandra Dominguini Daroldt e Simoni Leal Justo);

Capítulo V - Programa de educação pelo trabalho na saúde: tecnologias para a integralidade do cuidado na estratégia saúde na família (Luciane Besognin Ceretta, Lisiane Tuon Generoso Bitencourt, Mágada Tessmann Schwalm, Kelly Cristina Ferreira e Renan Antônio Ceretta);

Capítulo VI - O trabalho na estratégia saúde da família pelo olhar das agências comunitárias de saúde:reflexões para a educação em saúde (Janine Moreira, Heliete Rocha dos Santos, Elisabete Gonçalves, Fábio Cossa de Souza, Josiane Luzia Scussel e Patrícia Vieira);

Capítulo VII - Educação permanente em saúde: a roda de discussão na Estratégia da Saúde da Família - ESF (Cláudio Alex de Souza Sipriano).

Nessa obra, identifica-se a criação do SUS como uma manifestação do Estado Social, o qual se caracteriza, ao contrário do Estado Liberal, em ações e políticas públicas conducentes a efetivar os direitos sociais dos cidadãos, dos quais o direito à saúde é um dos seus expoentes máximos.

Através desta premissa, atrevemo-nos aqui a refletir um pouco sobre alguns fatos atuais que afetam este direito e cujo exemplo poderá, talvez, servir para agir melhor em situações futuras. Referimo-nos à crise econômica que atravessa Portugal e que, em 2010, levou este país a celebrar um acordo de resgate financeiro com a Troika, entidade composta pelo Fundo Monetário Internacional (FMI), Banco Central Europeu e Comissão Europeia. 
Portugal tem em comum com o Brasil o fato de consagrar na Constituição um direito à (proteção) da saúde (artigo 64 da Constituição da República Portuguesa) e de possuir um Serviço Nacional de Saúde (SNS), no qual se concretiza essencialmente aquele direito, pelo que a reflexão que desenvolvemos em seguida nos parece adequada.

Desde logo, o direito à saúde é um direito fundamental, com raízes em documentos internacionais de referência em direitos humanos, tal como o Pacto Internacional de Direitos Econômicos, Sociais e Culturais (1966), cujo artigo $12^{\circ}$ consagrou o "direito de todas as pessoas de gozar do melhor estado de saúde física e mental possível de atingir", definindo-se aí, também, as medidas necessárias a assegurar este direito: “a) a diminuição da mortinatalidade e da mortalidade infantil, bem como o são desenvolvimento da criança; b) o melhoramento de todos os aspetos de higiene do meio ambiente e da higiene industrial; c) a profilaxia, tratamento e controlo das doenças epidêmicas, endêmicas, profissionais e outras; d) a criação de condições próprias a assegurar a todas as pessoas serviços médicos e ajuda médica em caso de doença."

No entanto, apesar de não existir uma hierarquia formal entre os direitos humanos previstos nos documentos internacionais de referência, de que é expoente máximo a Declaração Universal dos Direitos Humanos (DUDH), mesmo uma análise meramente empírica da realidade mostra-nos que há direitos mais fáceis de defender em tribunal, direitos mais mediáticos e, sobretudo, que há direitos que são mais onerosos e envolvem mais recursos para concretizar do que outros, sendo ainda alvo de interesses económicos poderosos que tendem a dificultar a sua realização.

Ora, esta última situação aplica-se de forma ajustada ao direito à saúde, o que torna a garantia deste direito, na maioria dos países, num campo de batalhas judiciais, retóricas e económicas, onde nem sempre são vencedores os mais necessitados de proteção na sua saúde.

Este panorama tem-se agravado, não só fruto do aumento dos custos com medicinas e terapêuticas inovadoras e de ponta, mas, sobretudo, com as crises económicas que têm assolado um pouco por todo o lado o mundo em que vivemos e que nos últimos anos atingiram mesmo alguns países da União Europeia (Irlanda, Grécia, Espanha, Portugal e Itália). Na verdade, os estados de emergência financeira, onde as medidas de austeridade levam aos cortes drásticos em salários e políticas sociais, têm afetado nestes países a Saúde Pública, existindo estudos que 
comprovam já um aumento das taxas de mortalidade e dos suicídios, sabendo-se que a onda de choque ainda se fará sentir em anos futuros.

É de assinalar, por exemplo, que na Grécia a imprensa internacional e algumas entidades oficiais da Saúde Pública como o European Centre for Diseases Control (ECDC) começaram a dar o alerta para o retorno de mosquitos infetados com o vírus da malária naquele país, relacionando este facto com a crise económica e social que ali se vive. Para agravar este estado de coisas existem ainda estudos que provam que a mudança de paradigmas de organização da sociedade, verificada de forma aguda durante as crises, levam a um significativo aumento do estresse nas populações, aumentando os estilos de vida nocivos como o consumo de álcool e de outras substâncias aditivas e tóxicas. Sabendo-se que Portugal é já um país muito afetado pelas doenças mentais, é de prever o aumento destes casos com a crise, sabendo-se já que o número de casos de suicídio tem sido mais elevado nestes últimos anos.

São, pois, de diversa natureza os desafios que hoje se colocam à concretização do direito à saúde à escala global. Por isso são tão importantes as obras da natureza da que aqui apresentamos, dado que promovem o conhecimento sobre as políticas públicas em saúde e a sua eficácia no melhoramento das condições de vida das populações. É que, apesar de o cenário de realização do direito à saúde ser intrinsecamente dilemático, envolvendo decisões sensíveis como a alocação de recursos, há que nunca desistir do debate que envolve a procura de estratégias de solução equitativas e justas.

Estas estratégias devem incluir a utilização de grupos de pressão compostos por académicos e cientistas sociais na área do Direito Sanitário, os quais deverão fazer chegar o seu conhecimento aos órgãos decisores, para que estes possam criar as melhores políticas públicas e de combate à corrupção, no sentido de uma plena concretização do direito à saúde, meta que está longe de ser atingida para a maioria dos cidadãos do mundo atual.

O Direito tem um papel fundamental, pois muito se ganharia se simplesmente se cumprissem a Constituição e as leis, algo que em certos países parece esquecido. Em Portugal, por exemplo, são os próprios direitos constitucionais que se encontram em risco devido à crise e aos cortes na despesa pública ditados pelo programa de ajuste internacional, o qual tem tido a chancela de "transitório", mas sem se prever ainda o seu fim. Por outro lado, o aumento das "taxas moderadoras" no acesso aos 
serviços de saúde portugueses, instituído em 2011, tem tido enormes repercussões no direito à saúde dos cidadãos, limitando-o gravemente. O acordo feito com as entidades internacionais durante a conceção do programa de resgate previa o aumento das taxas moderadoras para incrementar a receita do Estado, mas sem que tivesse sido feito qualquer estudo de impacto destes aumentos sobre a saúde das populações.

Aquilo que aprendemos com a crise e a intervenção da Troika em Portugal, e que pode servir de aviso para outros países, foi que os direitos fundamentais consagrados na Constituição, tal como o direito à proteção da saúde, não estão a salvo de medidas restritivas dos mesmos, ou seja, este direito continua inscrito na Constituição tendo o Serviço Nacional de Saúde como o seu expoente de realização máximo. No entanto, as políticas públicas dos últimos três anos, em Portugal, têm-no esvaziado de forma grave.

O respeito pelos direitos consagrados na constituição, proveniente da representatividade que a eleição pelo povo deu aos deputados do parlamento, tem uma legitimidade legal e baseada em valores universais que não assistem às medidas de emergência decretadas por entidades externas à soberania do Estado, as quais são apenas normas casuísticas e de exceção, imbuídas de interesses pouco claros, acarretando todos os riscos da discricionariedade. No entanto, argumentos desta natureza em nada impediram o retrocesso na concretização dos direitos sociais dos cidadãos portugueses.

Podemos então perguntar-nos em que casos o direito constitucional à proteção da saúde, de que são titulares todos os cidadãos, quer no Brasil, quer em Portugal, poderá ser posto em causa, reduzido ou mesmo eliminado? Será que a redução de um défice pode ser razão suficiente para dificultar o acesso dos cidadãos aos serviços públicos de saúde, fazendo retroceder o direito à saúde?

A Constituição portuguesa diz que não, que os direitos fundamentais apenas podem ser alvo de exceções quando decretados o estado de sítio ou o estado de emergência (calamidade pública). No entanto, os direitos constitucionais têm sido restringidos em Portugal sem que aquelas situações de exceção tenham sido decretadas. O sistema de proteção dos direitos fundamentais dos cidadãos previsto na Constituição não tem funcionado, o que é muito preocupante.

Parece, pois, mesmo numa abordagem meramente empírica, não existirem quaisquer dúvidas sobre o fato de que as crises, sejam estas de natureza financeira, 
económica, política ou social (sendo a tendência para que todos estes elementos se acabem por juntar), afetam de forma inequívoca e multissetorial, direta e/ou indiretamente o estado de saúde de uma população.

No Brasil, o SUS representa um patrimônio coletivo da sociedade brasileira, dependente das políticas públicas de Estado, mas tal como em Portugal, não está ao abrigo de eventuais situações políticas, económicas e sociais que o possam minar parcial ou totalmente por meios mais ou menos diretos.

Daí que obras coletivas como o livro Temas em Direito Sanitário e Saúde Coletiva, se tornem tão relevantes, na medida em que trazem a lume a defesa e consolidação do direito à saúde e do SUS, afirmando o Direito Sanitário como instrumento de ação na promoção da garantia de políticas públicas conducentes à realização de um direito tão fundamental.

Toda a construção administrativa, social e legal que tem sido erigida no Brasil na promoção, defesa e concretização do direito à saúde e do SUS é já de uma dimensão muito considerável, tal como este livro bem testemunha.

Há que tornar essa realidade, da qual fazem parte instituições, profissionais de saúde e acadêmicos do Direito Sanitário em algo tão sólido que possa resistir ao tempo, às modas políticas e às crises, pois sem direito à saúde não há sociedade justa nem livre, nem economia sustentável.

VIEIRA, Reginaldo de Souza \& CERETTA, Luciene Bisognin (org.). Temas em direito sanitário e saúde coletiva: SUS - uma política pública de estado. Criciuma, SC (Brasil) : Ediunesc, 2013.

Contato e vendas:

editora@unesc.net ; livraria@unesc.net ; www.unesc.net/editora $+55.48 .3431 .2718$

Recebido para publicação em 22 de abril de 2014. Admitido para publicação em 12 de maio de 2014. 